\title{
Economics, ethics and climate change
}

\author{
Simon Dietz \\ London School of Economics and \\ Political Science and Tyndall Centre \\ for Climate Change Research, UK \\ s.dietz@Ise.ac.uk
}

\author{
Cameron Hepburn \\ James Martin Institute and School of \\ Enterprise and the Environment \\ University of Oxford and New College, \\ Oxford, UK \\ cameron.hepburn@economics.ox.ac.uk
}

\author{
Nicholas Stern \\ London School of Economics and \\ Political Science, UK \\ n.stern@lse.ac.uk
}

13 January 2008

\section{Introduction}

\begin{abstract}
If informed scrutiny by the public is central to any such social evaluation (as I believe is the case), the implicit values have to be made more explicit, rather than being shielded from scrutiny on the spurious ground that they are part of an "already available" metric that society can immediately use without further ado.
\end{abstract}

A. K. Sen (1999, p. 80) Development as Freedom.

There may never have been an instance of environmental pollution to challenge our powers of analysis and evaluation quite like climate change. Global in its causes and consequences, spanning many generations, and poorly understood but with the potential to transform the natural environment, climate change has highlighted challenging questions of the economics of risk, of distribution amongst individuals over space and time, and of different aspects of well-being. Any economic analysis of climate change policy must examine the conflicting interests of different people $^{1}$ and, indeed, consider the meaning and relevance of 'interest'.

It is not enough to simply presume that existing markets can provide a technocratic solution to ethical questions of intergenerational justice. Indeed, by its very nature climate change demands that a number of ethical perspectives be considered, of which standard welfare economics is just one. Other relevant and important approaches highlight rights, freedoms and the prevention of harm, as well as approaches based on virtues, as well as social contracts.

Furthermore, even if we accept the ethical tenets of the general welfare economics approach, the 'workhorse' model of standard welfare economics is one of several possible specifications. It has the merits of parsimony, but the disadvantages of incorporating a relatively restrictive ethical structure.

\footnotetext{
${ }^{1}$ A broader analysis could also give due consideration to the possible interests of non-humans, but this is very far detached from familiar approaches in economics, so we simply note as much at this point.
} 
Nevertheless, economics can provide valuable guidance on ethical issues by focusing on the consequences of policy and clarifying the implications of particular viewpoints on how to aggregate these consequences. But the relationship between economics and ethics cuts both ways: a careful, explicit examination of the relevant ethical issues can guide the formulation of economic questions on climate change and establish the meaning and relevance of the analysis.

In section 2, we set the standard welfare-economic approach to climate-change policy in the context of other major ethical perspectives. In section 3, we set out the dimensions of human well-being relevant to most ethical perspectives, along with the value judgements necessary for aggregation across those dimensions. The advantages and disadvantages of the various methods for determining value judgements are assessed in section 4, before these methods are applied in section 5 to three specific types of aggregation: temporal inequality, intra-temporal inequality and risk. Section 6 offers some brief concluding thoughts.

\section{Ethical perspectives}

Economists understand climate change to be an externality, just as they do, for example, noise pollution and traffic congestion. But, in comparison with most other externalities, climate change is much more encompassing.

First, it is global in its causes and consequences. On causes: almost all aspects of our daily lives are associated with the emission of greenhouse gases, whether directly or indirectly, and the warming caused by a tonne of greenhouse gases is independent of where in the world it is emitted. Responsibility is thus universal, but not equally shared. There are big differences in the volume of greenhouse gases that are and have been emitted in different parts of the world (also within countries and communities), both on aggregate and per capita. On consequences: the impacts of climate change will also be universal, more obviously so if the worst scenarios are realised. Ecosystems, their goods and services, depend on climatic conditions, so climate change threatens the basic elements of life for people around the world - access to water, food, health, and the use of land and the environment. But impacts will be very uneven. Geographically and economically vulnerable regions - and groups within regions - will experience the worst impacts, first. Other regions may even benefit from climate change, if the changes are small and gradual (and that is a big if: see Schellnhuber et al., 2006).

Second, the impacts of climate change are long-term and persistent. Once emitted, greenhouse gases can reside in the atmosphere for many decades (carbon dioxide can reside there for one or two centuries), and there is a lag in the response of the climate system to emissions and of ecological, social and economic systems to changes in climate, so the impacts of today's emissions last for centuries, and climatic changes today and in the near future depend on past emissions.

Thus, although ethical considerations are an essential feature of all public policy debates, they are fundamental in a particularly direct and obvious way to climate-change policy. Indeed, there are further ethical questions that climate change raises in common with other environmental externalities, most notably what ethical status should be given to the natural environment $?^{2}$ As should already be clear, while

\footnotetext{
${ }^{2}$ In this paper we will adopt a largely anthropocentric focus. Many important, contemporary contributions to the notion of intrinsic value in nature (that the natural environment is in itself morally considerable) were made in the 1970s by, for example, Naess (1973), Rolston (1975), Routley (1973), Singer (1977) and Goodpaster (1978). For recent reflections on its broader significance, for example to policy, compare Callicot (2002) to Norton (1992). A classic earlier account was written by Leopold (1949), while White's
} 
not primarily an ethical issue, the great uncertainty about the impacts of climate change and the (lesser) uncertainty about the costs of reducing greenhouse gas emissions are also relevant. ${ }^{3}$

Because of its great reach over many dimensions (e.g. time, space, states of nature and dimensions of human well-being), it is possible to take a wide variety of approaches to the ethics of climate change: standard welfare economics is just one. It is one of many approaches that look only at the consequences of actions (consequentialism) for the welfare or 'utility' of individuals in a community (perhaps most appropriately described by Sen as 'welfarism'), where utility is derived from the consumption of goods and services (assuming utility can be measured by the strength of everyone's preferences and these preferences can be described by the same utility function).

No ethical account is thereby taken of the actions by which consequences are caused. In contrast, 'deontological' ethical systems, including concepts of rights and freedoms, focus on the ethical qualities the 'rightness' or 'wrongness' - of actions in themselves, often setting out various duties and obligations. ${ }^{4}$ Although the consequences of actions play a constitutive role in understanding to what, for example, one has a right or freedom, modern-day proponents emphasise that such approaches can correct the more obviously egregious outcomes of unfettered preference-satisfaction utilitarianism, whereby the satisfaction of aggregated preferences can in principle mask great harm to a minority:

"It is quite likely that a cost-benefit analysis in ancient Rome of the spectacle of throwing Christians to the lions in the Colosseum would have come up with a positive result" (Beckerman and Pasek, 2001, p4). ${ }^{5}$

The predicted impacts of climate change raise questions of rights and corresponding duties. It is argued that future generations have the right to enjoy a world whose climate has not been transformed to compromise basic physical security (e.g. Shue, 1999) or result in other dangers (e.g. Caney, 2005, 2006). If this is so, the present generation should reduce greenhouse gas emissions to protect the rights of future generations. In terms of climate change in the next few decades, which largely cannot be avoided, industrialised countries are arguably duty-bound to compensate developing countries for the damage inflicted by past emissions (e.g. Mueller, 2006).

Rights to a stable climate might conflict with established rights to, for example, basic education and health, or to common treatment in voting. These established rights have very powerful consequences in terms of law, policy and structures of society. Ideally, all these rights would be fulfilled, but where a conflict of rights arises, one right will be violated and there will be a moral loss. Comparisons of the consequences may help determine which right takes priority. We will return to these issues shortly in discussing how comparisons of the consequences of climate policies are indispensable.

One might also seek to justify emission reductions based on the weaker notion that emitters of greenhouse gases (past, present and future) have obligations - not arising from rights - to consider the climate damage

(1967) essay on what he saw to be the damaging environmental ethic of Western philosophy and religion stimulated much of the subsequent work.

${ }^{3}$ See Gardiner (2004) on how uncertainty about climate change interacts with ethical considerations.

${ }^{4}$ The distinction between consequentialist and deontological approaches can be overstated. For instance, rule-utilitarianism can recognise the moral and social importance of rights and obligations (Harsanyi, 1980).

${ }^{5}$ Note however that Beckerman and Pasek (2001) are broadly supportive of a utilitarian perspective on long-term environmental problems. 
caused, just like a passer-by might be morally obliged to aid someone who has taken ill, even though the ill person is unlikely to have a right to that assistance as such. ${ }^{6}$ Barry (1999) constructs a theory of intergenerational justice that he argues does not depend on equal rights across generations. Instead, it depends only on the twin notions of 'responsibility' - that "bad outcomes for which somebody is not responsible provide a prima facie case for compensation" (p97) - and 'vital interests' - namely that there are certain objective requirements that all human beings have, regardless of their location in space or time.

A concept related to the idea of intergenerational obligations is that of sustainable development: future generations should have a standard of living - or at least the opportunities to attain a standard of living no lower than the current one. ${ }^{7}$ Economists have determined various rules implied by this definition of sustainable development, in terms of the capital stock passed from one generation to another (Dasgupta and Heal, 1974; Hartwick, 1977; Solow, 1974). These rules broadly focus on maintaining a constant overall stock of all forms of capital, including education, health, capital equipment, buildings, natural resources and the natural environment (some would also include social, cultural or institutional capital). If different forms of capital are substitutable to a degree, it follows that the natural environment need not be perfectly preserved for the next generation if they are provided with compensation in the form of another kind of capital.

Of course, it is impossible for the global environmental and ecological system, which provides us with life support functions such as stable and tolerable climatic conditions, to be substituted in its entirety. This has led to the development of special rules for the preservation of essential or so-called 'critical' environmental assets. The commitment of Article 2 of the United Nations Framework Convention on Climate Change to 'achieve stabilisation of greenhouse gas concentrations at a level that would prevent dangerous anthropogenic interference with the climate system' can be interpreted as just such a sustainability rule. The challenge is of course to establish what environmental assets are 'critical'.

The notion that moral obligations may exist without corresponding rights is also inherent in 'virtue ethics', which emphasises virtuous character as a guide to moral behaviour, rather than focusing on consequences or rules. These approaches enjoyed a renaissance in $20^{\text {th }}$ century Western moral philosophy, in large part because they may offer a more plausible explanation of how individuals actually think about ethics (Anscombe, 1958; Foot, 1978; Maclntyre, 1981; Wiggins, 2006). In the context of climate change, Jamieson (1992) has used virtue ethics to argue that our existing values are not up to the task presented by climate change, and that a change in values - virtues - is the only promising ethical approach. Interestingly, Crisp (1992) argues that utilitarianism (a consequentialist ethic) itself recommends pursuing a "life of virtue", and in the specific case of climate change, Jamieson (2007) insists "utilitarians should be virtue theorists".

Irrespective of which broader ethical framework is adopted, all frameworks will need some type of comparison of the consequences of climate change policies. For instance, we are likely to have to face trade-offs between minimal rights today to a basic standard of living, which might plausibly be compromised by very strong, very rapid reductions in greenhouse gas emissions, and counterpart rights in the far-off future, threatened by climate change. Further, everyday or 'first-order' morality (Wiggins, 2006) would seem to include the making of trade-offs in a consequentialist manner. As Sen noted, "the general

\footnotetext{
${ }^{6}$ Although in a number of jurisdictions there is in fact a legal requirement for the passer-by to provide assistance, for example in France and Germany.

${ }^{7}$ Jamieson (1998) provides a philosophical critique of the notion of sustainability.
} 
case for taking full note of results in judging policies and institutions is a momentous and plausible requirement" (1999, p 61).

\section{Dimensions of human well-being}

Different notions of consequentialist ethics emphasise different aspects of the consequences of decisions for present and future people and for the environment. Sen (1999) argues persuasively that relevant consequences not only include those for human well-being, but also those for human agency: individuals may seek to maximise objectives beyond their own well-being. In particular, Sen's focus on human capabilities, as well as outcomes, is relevant to climate-change policy and economics. While we do not pursue the capabilities approach here, we nevertheless consider it to have substantial potential as an ethical framework for climate change policy evaluation.

The lists of dimensions of human well-being that most consequentialist approaches would incorporate have strong similarities: above all consumption, education, health and environment. These are usually the areas of focus in cross-country comparisons of living standards, such as, for example, the World Development Indicators of the World Bank, the Human Development Report of the UNDP, and the UN Millennium Development Goals. Through these choices of data and corresponding goals, the international community has identified a strong and shared view of some of the key dimensions of human well-being.

How the implications on these four dimensions are assessed and aggregated, will, of course, vary according to the ethical position adopted. How and whether, in making assessments, we attempt to further aggregate over consequences (i) within generations, (ii) over time and (iii) according to risk will be crucial to policy design and choice. When we do aggregate explicitly, we have to compare quantitatively consequences of different kinds and for different people. These comparisons pose a new set of questions and problems.

While aggregation over the relevant dimensions helps to develop an understanding of the relative merits of different climate-change policies, it is also clear that many of the important issues arising from climate change are most obvious prior to aggregation into a single index such as world consumption. The aggregation will usually have to ignore or suppress crucial information, since data on key consequences or variables are unlikely to be available in a form amenable to aggregation for all dimensions.

Many decision-makers may feel able to formulate policies without an attempt at formal modelling, which explicitly aggregates effects over time, space, people, and possible random outcomes. The Stern Review (Stern, 2007) argued that decision-makers could form a reasoned view on whether they would spend (say) $1 \%$ of income a year to avoid the risk of the worst consequences of climate change. They can form that view from a description of these possible consequences, without necessarily attaching numbers to all the consequences, weighting them and adding them all up. In this more disaggregated approach, decisionmakers simply take a view on the broad description of future effects and do not need, for example, to specify social discount rates.

There will be some kind of implicit aggregation in many, but far from all, of the relevant judgements or decisions (for example, for some decisions only partial orderings may be needed, with very limited or no aggregation). But bringing aggregation out formally in terms of values, where it is otherwise implicit, can be helpful in highlighting areas of agreement and disagreement, as demonstrated by the discussion since publication of the Stern Review (see Dietz et al., 2007a,b; Beckerman and Hepburn, 2007). 


\section{Methods for determining values}

When decision makers do adopt an explicit aggregation process, an ethical framework must be selected and the values for explicit ethical parameters must be determined. Understandably, moral and political philosophers have had a great deal more to say about the derivation of moral values than economists. ${ }^{8}$ Most frequently, economists simply adopt a consequentialist, and specifically welfarist, perspective, where a social welfare function that is additive over individual utilities (without any weights) is specified. Then, in the case where a narrow consumption-based approach is followed, one assumes a particular form of utility function (such as the isoelastic function). Finally, within that particular specification, particular parameters need to be determined, such as the pure time discount rate $\delta$ and the social elasticity of marginal utility of consumption (or income) $\eta$. Yet each of these particular decisions has significant ethical implications. And an important metaethical question arises in making these explicit ethical choices: whose values should determine the ethical framework and the ethical parameters?

\subsection{Whose value judgements?}

The answer might be thought to depend, at least in part, upon the character of value judgements. One might start, for instance, from the position that certain ethical statements have an 'objective' character, so that careful thought ultimately leaves 'nothing else to think' (Wiggins, 1987, 2006). ${ }^{9}$ If this is so, then the views of expert moral philosophers - who have devoted more time and careful consideration to nuanced ethical questions than most of us - might be accorded particular weight..$^{10}$ On the other hand, even the most distinguished philosophers disagree on important ethical questions - Aristotle's defence of slavery in the Politics provides a case in point.

However, the fact that general ethical statements may be answered differently by different societies does not necessarily imply subjectivism (Mackie, 1977). Wiggins (2006, p. 347) draws an important and nuanced distinction between relativism and contextualism, pointing out that "no act or practice can be assessed as right or wrong, good or bad, etc. without the full specification of circumstances and context". For instance, humans might universally agree that immoral practices in one society are nevertheless perfectly moral in another. In other words, it is important to distinguish between general moral claims (in contrast to contextspecific moral claims) and universal moral claims (which are true from all vantage points). Moral objectivism, according to Wiggins (2006), amounts to the modestly optimistic claim that fully contextualised ethical propositions may find universal support.

Where ethical agreement cannot be found, some mechanism is needed to mediate between different perspectives and aggregate different value judgements for use in public decision making. Should the views of experts be accorded greater weight than those of the general public? There may be a parallel with the economic literature on biodiversity valuation, where Nunes and van den Bergh (2001) note the argument that lay people cannot judge the relevance and complexity of biodiversity and ecosystem functioning, so

\footnotetext{
${ }^{8}$ An inadequate and highly incomplete list would include the 'reflective equilibrium' notion of Rawls (1971), the 'argument from received opinion' discussed by Hare (1971), the use of opinion polls (Miller, 1999), the theory of 'discourse ethics' (Habermas, 1990) and works by Griffin (1996), Barry (1995) and others.

${ }^{9}$ For instance, in arguing for the fundamental nature of 'equality', but in stressing the question 'equality of what?', Sen (1992, p 1819) notes that "impartiality and equal concern, in some form or other, provide a shared background to all the major ethical and political proposals in this field that continue to receive argued support and reasoned defence."

${ }^{10}$ Even if moral philosophers are the best judges of ethical questions, political philosophers would note that it does not follow from the proposition that ' $X$ is the best judge' that ' $X$ should make the decision (or have a greater say)'.
} 
valuation should be left to experts such as biologists. In contrast, Arrow et al. (1993) recommend that lay people are sufficiently informed by experts before they express their valuations. Similarly, one might recommend that we should aggregate the ethical views of the general public, suitably informed and supported by expert philosophical guidance.

\subsection{Stated or revealed ethics?}

Ethical judgements and parameters might be determined through 'stated' approaches, which rely on people's explicit responses to questions or hypothetical thought experiments, or 'revealed' approaches, which attempt to deduce implicit ethical values from observed behaviour. Economists are familiar with the notion that behaviour can reveal implicit individual 'preferences', and some economists would further argue that appropriate ethical judgements can be deduced from these revealed preferences.

To deduce ethical values from preferences revealed by behaviour, at least four (non-trivial) conditions would be required: (i) a unique preference is revealed by the observed behaviour (the inverse optimum problem'); (ii) the preferences revealed are the 'true preferences' of the individual, based on full and correct information without any errors in decision-making; (iii) the preferences measured are contextually relevant to the ethical judgement at hand; and (iv) the preferences are appropriate for social decision making, and not merely individual decision making. If these four conditions are satisfied, the behaviour might 'reveal' an appropriate ethical view. The merit of the 'revealed ethics' approach is that the resulting ethical judgements are based upon real decisions, rather than hypothetical speculation. However, the four conditions set out above are rarely likely to be satisfied.

Condition (i) is unlikely to be satisfied because 'revealed ethics' approaches suffer from the 'inverse optimum' problem: underlying ethical values must be inferred from the observed behaviour, much as in standard consumer demand theory and estimation, and several different ethical perspectives may be consistent with the same behaviour. The outcome of this process depends on the assumptions about model structure and the representation and parameterisation of values. Stated approaches also suffer from an 'inverse optimum' problem, but it is not as severe, for the simple reason that stated approaches can be designed to elicit responses to the direct ethical issue at hand.

The second condition is that the revealed preferences are the true preferences of the individual. Harsanyi (1982, p. 55) noted that revealed preferences, or 'manifest preferences', may be "based on erroneous factual beliefs, or on careless logical analysis, or on strong emotions that at the moment greatly hinder rational choice". In contrast, 'true preferences' are the preferences that an individual would have if "he had all the relevant factual information, always reasoned with the greatest possible care, and were in a state of mind most conducive to rational choice" (Harsanyi 1982, p. 55) ${ }^{11}$ The distinction is not merely theoretical: people consistently mispredict the factors that determine their quality of life (e.g. Kahneman, Wakker and Sarin, 1997), and behave in a wide variety of suboptimal and irrational ways documented by psychologists and behavioural economists. In non-welfarist and non-utilitarian calculus, there may be merit in accepting people's errors and accounting for people's actual preferences, warts and all, because of the intrinsic value of the autonomy to make our own decisions. Interestingly, Harsanyi $(1982$, p. 56) went on to argue that 'manifest preferences' should count in assessments of welfare as "our final criterion in judging what his real interests are and what is really good for him". It is, however, perhaps more questionable whether

\footnotetext{
${ }^{11}$ Sen and Williams (1982) also note that individuals' actual preferences may, deliberately or accidentally, be very different from the preferences that would maximise their well-being.
} 
imperfect information and errors of analysis should be incorporated into an exercise intended to reveal ethical judgements.

Just as context matters to the formation of ethical judgements, as discussed above, it is also crucially important to observed behaviour, which makes condition (iii) unlikely to be satisfied. Levitt and List (2007, p. 162) conclude that behaviour is "affected by a dazzlingly complex set of relational situations, social norms, frames, past experiences, and the lessons gleaned from those experiences". If the objective is to determine an appropriate set of ethical judgements to inform climate-change policy, the revealed preferences should be derived from individual behaviour in a context that maps appropriately onto an international, intergenerational, non-marginal, risky and uncertain environmental policy problem. Behaviour revealed in one setting does not necessarily map neatly onto other settings, just as insights from a carefully controlled scientific laboratory experiment in a vacuum do not apply perfectly to a real-world situation with friction. And human behaviour is even less likely to be replicated outside the laboratory (Levitt and List, 2007).

Sen (1992, p. 19) clearly articulates the distinction between questions of political philosophy regarding social arrangements, on the one hand, and those of personal ethics on the other, putting condition (iv) into question. He notes that in "the ethics of personal behaviour, powerful arguments have been presented in favour of permitting or requiring explicit asymmetries in the treatment of different people. Such arguments may relate, for example, to the permissibility-perhaps even the necessity-of paying special attention to one's own interests...[and]...one's own family members and others to whom one is 'tied"'. It is not impossible, for instance, that many people would behave according to some agent-relative ethic in their individual decisions, placing a greater weight on the interests of family, friends and others within close communities. And yet, in considering what 'we' should do about policy issues such as climate change, the same people might wish to adopt an impartial ethic. More generally, the ethics revealed from individual behaviour may be an inappropriate guide to the same individual's ethical values for social decisions.

For these four reasons, ${ }^{12}$ great caution is warranted when using 'revealed ethics' approaches to determine appropriate value judgements for social decision making. This is not to ignore the problems in 'stated ethics' approaches, which mirror the problems documented in the contingent valuation literature. ${ }^{13}$ But 'stated ethics' approaches are less likely than 'revealed ethics' approaches: (i) to cause difficulty with the inverse optimum problem; (ii) to misrepresent the true preferences; (iii) to be contextually inappropriate; and (iv) to reveal personal ethics rather than values for political philosophy. Stated approaches also provide more opportunity for the input of philosophical expertise to the formation of ethical judgements than revealed approaches.

Whether a stated or revealed ethics approach is employed, a mechanism is required to aggregate the views of the individuals whose preferences are deemed to count. Economists reach almost instinctively to the markets when in need of an aggregation device, and we consider the relevance of market data now.

\footnotetext{
${ }^{12}$ Harsanyi (1982, p. 56) might have added a fifth, arguing that "we must exclude all clearly antisocial preferences, such as sadism, envy, resentment, and malice".

${ }^{13}$ See, e.g. Carson (2000).
} 


\subsection{The relevance of market data}

Markets (at least in the narrow sense of aggregate market demand and supplies) provide a 'revealed ethics' approach that automatically aggregates individual preferences. They may, therefore, appear to be an obvious device to aggregate individual value judgements about social problems such as climate change. Indeed, some economists have asserted that deep ethical questions involved in climate-change policy, such as the appropriate weight to place on future generations interests, should be resolved by reference to market data (Nordhaus, 2007; Weitzman, 2007). However, there at least five additional reasons, beyond the four caveats discussed above, to be cautious in employing market data for ethical values generally, and for climate-change ethics in particular.

First, the standard problems of market imperfections distort market valuations from shadow prices or social valuations. Drèze and Stern $(1987,1990)$ provide a detailed and formal analysis of relations between market imperfections, shadow prices and market prices in a general equilibrium framework.

Second, markets aggregate preferences with a weighting applied to those who participate more heavily. This tends to imply that the preferences of the wealthy (rather than the more 'expert', for instance) count more in determining overall social ethical judgements. For example, actual savings rates do not represent equally aggregated ethical judgements in an optimisation problem, but instead are the result of a complex process of interaction, where different agents have different endowments and bargaining power, and where the decisions of those with more wealth have a greater impact on overall savings rates.

Third, futures markets exist only over a few decades and do not cover the very long periods, i.e. centuries, relevant for the discussion of climate change. Markets therefore cannot directly reveal appropriate ethical parameters beyond their horizons. Furthermore, as markets only aggregate the preferences of the people participating on them, the interests of future generations are not incorporated, even though they are the ones most profoundly affected by climate change.

Fourth, and this is related to the fourth general condition about 'revealed ethics' in section 4.2, individual decision making on markets will (appropriately) reflect individual, rather than social concerns. Market data does not reflect an answer to the question of what citizens of a society should do when considering together what they would regard as the right or responsible action. For instance, the probability of demise for an individual is much higher than that of the probability of demise for humanity as a whole (which is relevant to the appropriate pure time discount rate, $\delta$ ).

Fifth, markets are unable to capture the ethical issues associated with non-marginal and irreversible change at the global level, since any one individual's action will not affect the set of aggregate circumstances.

In our view, the issues we face as a result of climate change raise very difficult philosophical questions, versions of which have challenged the philosophers across the ages. There is no alternative to engaging in a normative discussion. Some may seek to argue the case that markets are the appropriate device to both reveal and aggregate ethical judgements. Many others will find this an implausible position. Irrespective, the ethical issues cannot be side-stepped, even by those wanting to resort to market information to reveal the answers to philosophical questions.

\section{Values for aggregation}

We now illustrate some of the above issues using the very simple structures from welfare economics, as it has come to be standardly applied to climate change in the past twenty years or so (beginning with Cline, 1992; Manne et al., 1995; Nordhaus, 1994; Tol, 1997; and others). 


\subsection{Model structure}

In brief, the standard, 'workhorse' model of welfare economics in this case specifies a particular BergsonSamuelson social welfare function that is additive over the utilities of all individuals in all time-periods (without any weights):

$$
W=\sum_{t=0}^{T} \sum_{i=1}^{N_{t}}\left(u_{i, t}\right)(1+\delta)^{-t}
$$

Where $W$ is aggregate social welfare, $u$ is the utility of individual $i$, and there are $N_{t}$ individuals in time period $t$. It is simplest in this case to think of the specification for the function $u($.) as a social representation and not a cardinal measure of utility. Importantly, the contribution to social welfare of utility in different time periods is a function of the utility discount rate or pure rate of time preference, $\delta$. This is a weighting of utilities in different periods purely because of the different dates and is quite separate from the circumstances of individuals at these times. In the Stern Review (Stern, 2007), this was set to $0.1 \%$ per annum. Cline (1992) similarly set $\delta=0$. However, doing so has revealed a singular disagreement between climate-change economists, many of whom (e.g. Nordhaus, 2007; Weitzman, 2007) prefer to set $\delta$ in the region of $2-3 \%$ per annum. We shall outline the nature of the disagreement below.

To simplify the analysis greatly, the utility of individuals in major regions of the world is aggregated into a single, representative individual and multiplied by the size of that region's population:

$$
W=\sum_{t=0}^{T} \sum_{j=1}^{J}\left(u_{j, t} N_{j, t}\right)(1+\delta)^{-t}
$$

where $j$ is the region, of which there are a total of $J$. Note that this formulation depends on the assumption that the population is exogenous. If the total size of the population may be measurably affected by climate change and in turn by policy, more difficult ethical issues arise (see Dasgupta, 2001; Broome, 2004; 2005).

The utility of the representative individual in each region is described by a utility function, where utility depends only on the aggregate consumption of goods and services via an isoelastic function. The impacts of climate change are expressed relative to a loss in this consumption:

$$
u_{j, t}=u\left(c_{j, t}\right)=\frac{c_{j, t}{ }^{1-\eta}}{1-\eta}
$$

where $c$ is the consumption of the representative individual for region $j$. The assumptions behind the workhorse model imply that the elasticity of marginal utility with respect to consumption, $\eta$, is effectively a coefficient of social inequality aversion, in particular to the distribution of consumption across individuals. In a model with many countries and many time-periods, inequality is relevant across space at a given point in time (intra-generational distribution) and over time (inter-temporal allocation). Further, under uncertainty about future consumption that can be described by a distribution of subjective probabilities, $\eta$ is a coefficient of relative risk aversion:

$$
\mathrm{E}(W)=\sum_{p} p_{s} \sum_{t=0}^{T} \sum_{j=1}^{J}\left(u_{j, t, s} N_{j, t, s}\right)(1+\delta)^{-t}
$$


where $s$ is a particular climate-change scenario, the probability of each scenario being $p_{s}$, and $E(W)$ denotes the fact that the weighted sum of all utilities is now a measure of expected utility.

So, because of the simplifications employed in the conventional model, the value for $\eta$ captures our attitudes to risk, inequality within generations and inequality between generations. In the base case of the Stern Review and indeed in many other welfare-economic analyses of climate change, $\eta$ is set to unity (which gives a special form for equation (3), namely $u_{j}=\ln c_{j}$ ). Any particular choice of $\eta$ is likely to be contested, including $\eta=1$, and thus sensitivity analysis is important. Part of the problem in interpreting and discussing $\eta$ arises because the simplifying assumptions of the standard model leave $\eta$ to reflect three related but distinct concepts simultaneously. This is problematic, because a great deal of information appears to be of relevance to $\eta$ and yet it is contradictory.

Indeed, it is not intuitively obvious whether an increase in $\eta$ would produce an increase or a decrease in the calculated impact of climate change on social welfare. First, higher $\eta$ implies greater risk aversion, which in turn implies greater concern about the worst climate-change scenarios, and a higher impact of climate change on social welfare. Second, higher $\eta$ also implies greater social inequality aversion, increasing the relative weight placed on changes in the consumption of the poor, so that greater weight is placed on climate impacts in the poorest regions. Since climate change is expected to hit the poorest regions hardest in relative terms, higher $\eta$ in this respect increases the overall loss in social welfare. Third, if we also assume, as is standard, that aggregate consumption will continue to grow despite climate change, then the overall loss in social welfare falls with higher $\eta$, because it reduces the weight placed on future consumption, and increases the weight placed on present consumption (because the present is poorer than the future). This effect reduces the estimated net impact of climate change, because the impacts of climate change will be mainly felt in the (relatively rich) future. Dietz et al. (2007c) model the contrasting effects of risk aversion and intertemporal inequality aversion.

Is there any justification for using the one parameter to reflect aversion to risk, aversion to intra-temporal inequality, and aversion to inequality through time? Harsanyi (1953) thought so. He considered the perspective of a Kantian impartial observer (or someone in Rawl's (1971) "original position"), with an equal chance of being born into the place of any individual. He argued that this suggested "a close affinity" between individual risk preferences and social inequality preferences. The analogy between risk and inequality from behind the "veil of ignorance" has proven powerful (Sen, 1978; Broome 1990). However, it is a substantial leap to conclude that the two concepts are identical. Empirical evidence suggests the concepts are distinct (e.g. Carlsson et al., 2005). At an individual level, Beckerman and Hepburn (2007) note that a person might not be very risk averse (low $\eta$ ), yet be strongly averse to inequality (high $\eta$ ). And a risk-averse person (high $\eta$ ) may care little about inequality of outcomes (low $\eta$ ). At a social level, we might be very averse to climate risks (high $\eta$ ), while accepting inequalities in outcomes (low $\eta$ ) because, say, we also value equality of opportunities or capabilities. ${ }^{14}$

Research on subjective well-being further suggests an important difference between inequality within a generation, and inequality between generations. Di Tella and MacCulloch (2006) conclude that evidence on happiness is consistent with the notion that happiness is derived from relative levels of consumption,

\footnotetext{
14 Harsanyi's (1955) theorem shows that if social preferences satisfy the Pareto principle for prospects (which amounts to weak separability across people), and they satisfy expected utility theory (which amounts to strong separability across states of nature), then risk aversion is the same as inequality aversion. For people's preferences to embody a degree of risk aversion that is different from their degree of inequality aversion, their preferences either do not satisfy expected utility theory, or they do not satisfy the Pareto principle for prospects.
} 
suggesting that spatial or intra-generational inequality matters. But it also reveals that aggregate happiness remains relatively constant over time (Easterlin, 1974, 1995), suggesting that inequality in consumption over time is less important.

These reasons suggest that combining value judgements on risk, intertemporal inequality and intratemporal inequality into one parameter may be a non-trivial simplification. It is certainly not necessary. Kreps and Porteus (1978), Selden (1978) and Epstein and Zin (1989) specify models that disentangle risk aversion from intertemporal substitution and these models may be better suited to economic analysis of climate change. This is an area for further research. With this in mind, we now examine arguments for different values of $\eta$ derived from considerations about risk, space and time respectively.

\subsection{Risk}

How can we use observed attitudes to risk to illuminate the choice of $\eta$ ? Gollier (2006), in reviewing the Stern Review's welfare-economic analysis, has argued that some studies of insurance point to higher values of $\eta$ from 2 to 4 . Equally, however, some interpretations of gambling behaviour suggest low or negative $\eta$. And much theoretical and empirical work on choice and risk has argued that the expected-utility model performs very badly indeed. It is very difficult to use empirical evidence on risk aversion to narrow down a relevant range for $\eta$. The reasons are first that the expected-utility model is so often in contradiction with the data, second, where it is not necessarily in contradiction with the data, the range of possible values of $\eta$ is very wide, and third, as discussed in section 4 , the coefficients of risk aversion as revealed by aggregated market decisions may have limited normative significance for the economics of climate change.

\subsection{Intra-temporal allocation}

Dasgupta (2006) argues for values of $\eta$ from 2 to 4 on normative grounds. In contrast, Atkinson and Brandolini (2007) point out that, if one examines the behaviour of public decision-making, there are plausible reasons to think $\eta$ is lower than unity in practice. Following Okun's (1975) 'leaky bucket' experiment, consider the desirability of a transfer from individual A to individual B, where A has income, say, twice that of B. If $\eta=1$, so that the elasticity of social marginal utility of income (using income and consumption interchangeably, for simplicity) falls as the reciprocal of income, then a transfer of a unit of income from A to B increases welfare provided not more than $50 \%$ is lost 'along the way' or 'leaked out of the bucket'. A recent estimate of income distribution for the USA suggests that income at the 90th percentile (i.e. the income of a person with $90 \%$ of the population earning less), is roughly twice income at the $50^{\text {th }}$ percentile, which is again roughly twice that at the $25^{\text {th }}$ percentile. Assuming $\eta=1$, a transfer from P90 to P10 would be accepted provided no more than $87.5 \%$ is 'lost along the way'. The 'loss along the way' can stand for many possibilities, such as the actual administrative costs of making transfers, disincentives, corruption and so on. Those who consider a loss of $87.5 \%$ to be too high would consider $\eta=1$ to be too high in this context. ${ }^{15}$

Further, Atkinson and Brandolini (2007) argue that assuming $\eta$ to be constant with changing consumption or income is unhelpfully restrictive. For instance, the appropriate elasticity may be low or zero (constant marginal utility of income if zero) for people living below the poverty line. And many would argue that there is very little social benefit in redistributing income amongst the rich (e.g. within the top $5 \%$ or $1 \%$ of the distribution). These views would point to an elasticity that first rises as income rises, then falls. We would not necessarily insist on a curve of this shape, but more generally highlight the straightjacket of a

\footnotetext{
${ }^{15}$ If the commonly used Gini coefficient is interpreted as a welfare index (e.g. Sen 1997), the appropriate curve would be much flatter, in this sense similar in effect to $\eta$ lower than unity.
} 
constant $\eta$. The primary argument for employing constant $\eta$ is convenience, but we must be aware of its limitations. We should also note that in many examples of cost-benefit analysis of projects as practised by public-sector economists, there is no weighting for intra-temporal income differences: in other words $\eta$ is equal to zero.

Our conclusion from this discussion of intra-generational transfers and inequality measures is that, if a constant elasticity of consumption measure is to be used, then while some observers would view $\eta=1$ to be too low, others would consider it rather high. On the other hand, with a non-constant $\eta$, the value could be higher than one in some parts of the income range and lower than one elsewhere.

\subsection{Time}

Building on the model structure above, many find it helpful to think about intertemporal value judgements in terms of the social rate of time preference or social discount rate. The social discount rate $r$ in this model is:

$$
r=\eta g+\delta
$$

where $g$ is the rate of consumption growth per capita. We must clearly distinguish between $r$, the social discount rate, and $\delta$, the pure time or utility discount rate. The latter is an integral feature of the canonical model of social welfare presented above and is a primary ethical object. That is, its ethical status requires careful consideration. The former is the discount rate on consumption, not utility, and can be used where the project under evaluation is marginal to the path of future consumption. We cannot make this assumption in the case of climate change, where the impacts are potentially non-marginal in that they could significantly reduce the growth rate (inclusive of the impacts of climate change on income and welfare) at some point in the future.

As noted, $\delta$ has a direct ethical meaning: it determines the weight placed on the utility of people born at different times. The classical utilitarian approach in equation (1), taking the sum of (unweighted) utilities, assumes that individuals should be treated equally and symmetrically. Discrimination by date of birth is then also difficult to justify. Yet if $\delta=3 \%$ per annum, as suggested by some climate-change economists (e.g. Nordhaus, 2007), someone born in 1960 should 'count' for roughly twice someone born in 1985 . This is implausible. The Stern Review (Stern, 2007) argued that the most straightforward ethical approach to understanding $\delta$ was through the interpretation of $(1+\delta)^{-t}$ as the probability of existence of future human civilisations, and $\delta$ was set to $0.1 \%$ per annum. Many would see the implied $90 \%$ chance of human civilisation seeing out this century to be alarmingly low, although Rees (2003) has put the chance at $50 \%$.

However, the combination of an ethical choice such as $\delta=0.1 \%$ with an elasticity of marginal utility of $\eta=1$ places quite heavy weight on benefits far into the future. One way of illustrating this is to note that if the long-run growth rate of consumption is $g$ (and suppose that eventually population growth is zero), then the utility integral over infinity converges if and only if (see Stern, 2007, p58 and p670):

$$
\delta>(1-\eta) g
$$


If $\eta$ is less than one and $\delta$ is low, this condition would be violated. ${ }^{16}$ Cline (2007), in his review of the Stern Review, has emphasised that the combination of $\eta=1$ and $\delta=0.1 \%$ implies that the weight placed on the impacts of climate change in the very far-off future is large. The empirical models used by climate-change economists typically have a fixed time-horizon of one to three centuries, ${ }^{17}$ so the impacts in question are extrapolations from beyond the end of the modelling horizon. This would be less of a problem if $\delta$ and $\eta$ were higher, because the share of the present value of climate impacts in the distant future would be lower (Dietz et al., 2007b). However, this is not an appropriate reason for the choice of ethical parameters.

If an ethical observer knows what the future ethical savings rate should be, then there is another link between $\eta$ and $\delta$. Dasgupta (2006) and Nordhaus (2007) compare the optimal savings rate implied by $\eta=1$ and $\delta=0.1 \%$ (as in the Stern Review) with observed savings rates today. They suggest that the implied optimal savings rates are higher than observed rates, and conclude that this combination of parameters is inappropriate. There are three responses. First, currently observed savings rates may not be long-run ethical savings rates. Second, there are many savings rates to observe, from around zero or less in the USA, to over $50 \%$ in China. Third, this is an 'inverse optimum problem', where their conclusion is dependent on the model structure assumed. In a very simple model of production where consumption growth derives solely from the returns to investment in (man-made) capital, $\eta=1$ and $\delta=0.1 \%$ would lead to very high optimal savings rates. Adding technical progress can bring optimal savings rates down to current levels in industrialised countries. This was known to Keynes and Ramsey and is considered in some detail by Mirrlees and Stern (1972).

\section{Conclusion}

Climate change has highlighted challenging questions in the economics of risk, of distribution amongst individuals, of distribution over time and generations, and of different aspects of well-being. Explicit aggregation of all effects into one model is not necessary for a reasoned judgement of whether the costs of taking action on climate change justify the benefits of damages avoided. However, whichever approach is followed, reasoned judgement is impossible without considering difficult ethical issues, taking most economists into unfamiliar territory. We are fortunate to have intellectual leaders such as Amartya Sen to provide us with guidance on the boundaries of ethics and economics.

This guidance reveals several important insights. Because climate change is a non-marginal, international, inter-generational policy challenge, involving important questions of risk and uncertainty, our usual shortcuts are inappropriate. Moreover, existing markets do not provide a technocratic solution to questions of intergenerational justice. Instead, climate change demands that a number of ethical perspectives be considered. Standard welfare economics is one such perspective. Other perspectives, not least Amartya Sen's capabilities approach, deserve more detailed application beyond the ambit of this paper.

Even if we accept the ethical tenets of the general welfare economics approach, this paper has argued that the 'workhorse' model of standard welfare economics has a relatively restrictive structure. The simplifying assumptions that make the model so tractable and useful, also imply that three distinct and important ethical concepts are represented in the one parameter. Specifying a richer welfare economic model is likely to have a significant impact on results in the economics of climate change.

\footnotetext{
${ }^{16}$ In assessing this observation we should, however, note that the condition for convergence applies to the very long run or to limiting values of the elements in equation (6). There is no reason to suppose that in the short, medium and long run any of them are constant.

${ }^{17}$ For example, the PAGE model used by the Stern Review runs until 2200 (Hope, 2006).
} 
Economics can provide valuable guidance on ethical issues by focusing on the consequences of policy and clarifying the implications of particular viewpoints on how to aggregate these consequences. In this respect, sensitivity analyses in formal models perform the very important function of allowing the consequences of different ethical parameters to be explored. But the relationship between economics and ethics cuts both ways: a careful, explicit examination of the relevant ethical issues can guide the formulation of economic questions on climate change and illuminate the meaning and relevance of the analysis.

\section{Acknowledgements}

We thank Tony Atkinson, John Broome, Simon Caney, Partha Dasgupta, Stephen Gardiner, Roger Guesnerie, Claude Henry, David Newbery, Bill Nordhaus, Tony Venables and Martin Weitzman for discussion of these issues. We are also grateful to participants in the Climate Change and Global Justice conference at the Department of Politics and International Relations, University of Oxford, 21-22 September 2007. 


\section{References}

Anscombe, G. E. M. (1958). "Modern moral philosophy." Philosophy 33(124): 1-19.

Arrow, K. A., R. Solow, P. R. Portney, E. E. Leamer, R. Radner and H. Schuman (1993). Report of the NOAA Panel on Contingent Valuation.

Atkinson, T. and A. Brandolini (2007). On Analysing the World Distribution of Income, Oxford University.

Barry, B. (1995). Justice as Impartiality. Oxford, Oxford University Press.

Barry, B. (1999). Sustainability and intergenerational justice. Fairness and Futurity. A. Dobson. Oxford, Oxford University Press.

Beckerman, W. and J. Pasek (2001). Justice, Posterity, and the Environment. Oxford, Oxford University Press.

Beckerman, W. and C. J. Hepburn (2007). "Ethics of the discount rate in the Stern Review." World Economics 8(1): 187-210.

Broome, J. (1990) Weighing Goods. Oxford: Basil Blackwell.

Broome, J. (2004). Weighing Lives. Oxford, Oxford University Press.

Broome, J. (2005). "Should we value population?" The Journal of Political Philosophy 13(4): 399-413.

Caney, S. (2005), 'Cosmopolitan Justice, Responsibility and Global Climate Change', Leiden Journal of International Law 18(4) pp.747-775.

Caney, S. (2006), "Global Justice, Rights and Climate Change." Canadian Journal of Law and Jurisprudence XIX(2), pp.255-278.

Carlsson, F., D. Daruvala and O. Johansson-Stenman (2005). "Are people inequality-averse, or just riskaverse?" Economica 72(287): 375-396.

Carson, R. T. (2000). "Contingent valuation: a user's guide." Environmental Science and Technology 34: 1413-1418.

Cline, W. (1992). The Economics of Global Warming. Washington, Institute for International Economics.

Cline, W. (2007). Evaluating the Stern Review on the Economics of Climate Change, Center for Global Development and Peterson Institute for International Economics.

Crisp, R. (1992). "Utilitarianism and the Life of Virtue," Philosophical Quarterly 42: 139-60.

Dasgupta, P. (2001). Human Well-Being and the Natural Environment. Oxford, Oxford University Press. 
Dasgupta, P. (2006). Comments on the Stern Review's Economics of Climate Change, University of Cambridge.

Dasgupta, P. and M. G. Heal (1974). "The optimal depletion of exhaustible resources." Review of Economic Studies 41(S): 3-28.

Dietz, S., C. Hope, N. Stern and D. Zenghelis (2007a). "Reflections on the Stern Review (1): a robust case for strong action to reduce the risks of climate change." World Economics 8(1): 121-168.

Dietz, S., D. Anderson, N. Stern, C. Taylor and D. Zenghelis (2007b). "Right for the right reasons: a final rejoinder on the Stern Review." World Economics 8(2): 229-258.

Dietz, S., C. Hope and N. Patmore (2007c). "Some economics of 'dangerous' climate change: reflections on the Stern Review." Global Environmental Change 17(3-4): 311-325.

Di Tella, R. and R. MacCulloch (2006). "Some uses of happiness data in economics." Journal of Economic Perspectives 20(1): 25-46.

Easterlin, R. A. (1974). Does Economic Growth Improve the Human Lot? Some Empirical Evidence. Essays in Honor of Moses Abramovitz. P. A. David and M. W. Reder. New York, Academic Press: 89-125.

Easterlin, R. A. (1995). "Will raising the incomes of all increase the happiness of all?" Journal of Economic Behavior and Organization 27(1): 35-47.

Epstein, L. G. and S. E. Zin (1989). "Substitution, risk aversion and the temporal behavior of consumption and asset returns: a theoretical framework." Econometrica 57(4): 937-969.

Foot, P. (1978). Virtues and Vices and Other Essays in Moral Philosophy. Oxford, Blackwell.

Friedman, M. and Savage, L. J. (1948) "The Utility Analysis of Choices Involving Risk," Journal of Political Economy, 56: 279-304;

Gardiner, S. (2004). "Ethics and global climate change." Ethics 114: 555-600.

Gollier, C. (2006). Institute Outlook: Climate Change and Insurance: An Evaluation of the Stern Report on the Economics of Climate Change, Barbon Institute.

Goodpaster, K. E. (1978). "On being morally considerable." Journal of Philosophy 75: 308-325.

Griffin, J. (1996) Value Judgement: Improving our Ethical Beliefs. Oxford, Clarendon Press.

Hare, R. M. (1971). Essays on Philosophical Method Berkeley, University of California Press.

Habermas, J. (1990). Moral Consciousness and Communicative Action, Cambridge, MIT Press.

Harsanyi, J. C. (1953). "Cardinal utility in welfare economics and in the theory of risk-taking." The Journal of Political Economy 61(5): 434-435. 
Harsanyi, J. C. (1955). "Cardinal welfare, individualistic ethics, and interpersonal comparisons of utility." The Journal of Political Economy 63(4): 309-321.

Harsanyi, J. C. (1980). "Rule utilitarianism, rights, obligations and the theory of rational behavior" Theory and Decision 12(2): 115-133.

Harsanyi, J. C. (1982). Morality and the theory of rational behavior. Utilitarianism and Beyond. A. K. Sen and B. Williams. Cambridge, UK, Cambridge University Press: 39-62.

Hartwick, J. M. (1977). "Intergenerational equity and the investing of rents of exhaustible resources." American Economic Review 67(5): 972-974.

Hope, C. (2006). "The marginal impact of CO2 from PAGE2002: an integrated assessment model incorporating the IPCC's five reasons for concern." Integrated Assessment 6(1): 19-56.

Jamieson, D. (1998). "Sustainability and beyond." Ecological Economics 24(2-3): 183-192.

Jamieson, D. (1992). "Ethics, public policy and global warming." Science, Technology and Human Values 17: 139-153.

Jamieson, D. (2007). "When utilitarians should be virtue theorists" Utilitas 19(2): 160-183.

Kahneman, D., P. P. Wakker and R. Sarin (1997). "Back to Bentham? Explorations of experienced utility." Quarterly Journal of Economics 112(2): 375-405.

Kreps, D. M. and E. L. Porteus (1978). "Temporal resolution of uncertainty and dynamic choice theory." Econometrica 46(1): 185-200.

Leopold, A. (1949). A Sand County Almanac, and Sketches Here and There. New York, Oxford University Press.

Levitt, S. D. and J. List (2007). "What do laboratory experiments tell us about the real world?" Journal of Economic Perspectives 21(2): 153-174.

MacIntyre, A. (1981). After Virtue: A Study in Moral Theory. London, Duckworth.

Mackie, J. L. (1977). Ethics: Inventing Right and Wrong. Harmondsworth, Penguin.

Manne, A. S., R. Mendelsohn and R. G. Richels (1995). "MERGE - a model for evaluating regional and global effects of GHG reduction policies." Energy Policy 23(1): 17-34.

Miller, D. (1999). Principles of social justice. Harvard: Harvard University Press.

Mirrlees, J. A. and N. H. Stern (1972). "Fairly good plans." Journal of Economic Theory 4(2): 268-288.

Mueller, B. (2006). Adaptation Funding and the World Bank Investment Framework Initiative. Background Report prepared for the Gleneagles Dialogue Government Working Groups Mexico, 7-9 June 2006. 
Naess, A. (1973). "The shallow and the deep, long range ecology movements: a summary." Inquiry 16: 95100.

Nordhaus, W. D. (1994). Managing the Global Commons: the Economics of Climate Change. Cambridge, Mass, MIT Press.

Nordhaus, W. D. (2007). "A Review of the Stern Review on the Economics of Climate Change." Journal of Economic Literature 45(3): 686-702.

Norton, B. G. (1992). "Epistemology and environmental values." The Monist 75: 208-226.

Nunes, P. A. L. D. and J. C. J. M. van den Bergh (2001). "Economic valuation of biodiversity: sense or nonsense?" Ecological Economics 39(2): 203-222.

Okun, A. M. (1975). Equality and Efficiency, the Big Tradeoff. Washington, The Brookings Institution.

Rawls, J. (1971). A Theory of Justice. Oxford, Oxford University Press.

Rees, M. J. (2003). Our Final Century: a Scientist's Warning. London, Heinemann.

Rolston III, H. (1975). "Is there an ecological ethic?" Ethics 85: 93-109.

Routley, R. (1973). Is there a need for a new, an environmental ethic? Proceedings, 15th World Corgress of Philosophy. 1: 205-210.

Schellnhuber, H. J., W. Cramer, N. Nakicenovic, T. Wigley and G. W. Yohe (2006). Avoiding Dangerous Climate Change. Cambridge, UK, Cambridge University Press.

Selden, L. R. (1979). "An OCE analysis of the effect of uncertainty on saving under risk preference independence." The Review of Economic Studies 46(1): 73-82.

Sen, A. K. (1972). "Control areas and accounting prices: an approach to economic evaluation." Economic Journal 82(325): 486-501.

Sen, A. K. (1992). Inequality Reexamined. New York; Cambridge, Mass., Russell Sage Foundation; Harvard University Press.

Sen, A. K. (1999). Development as Freedom. New York, Knopf.

Sen, A. K. and B. Williams (1982). Utilitarianism and Beyond. Cambridge, Cambridge University Press.

Shue, H. (1999). Bequeathing hazards: security rights and property rights of future humans. Global Environmental Economics: Equity and the Limits to Markets. M. Dore and T. Mount. Oxford, Blackwell: 3853.

Singer, P. (1977). Animal Liberation: A New Ethics for Our Treatment of Animals. New York, Avon. 
Solow, R. M. (1974). "Intergenerational equity and exhaustible resources." Review of Economic Studies Symposium: 29-46.

Stern, N. (2007). The Economics of Climate Change: The Stern Review. Cambridge, UK, Cambridge University Press.

Tol, R. S. J. (1997). "On the optimal control of carbon dioxide emissions: an application of FUND." Environmental Modelling and Assessment 2: 151-163.

Weitzman, M. L. (2007). "A Review of the Stern Review on the Economics of Climate Change." Journal of Economic Literature 45(3): 703-724.

White Jr., L. (1967). "The historical roots of our ecological crisis." Science 155: 1203-1207.

Wiggins, D. (1987). Needs, Values, Truth. Oxford, Blackwell.

Wiggins, D. (2006). Ethics: Twelve Lectures on the Philosophy of Morality. London, Penguin. 